\title{
Impact of Solar Light and Electricity on the Quality and Timeliness of Maternity Care: A Stepped-Wedge Cluster- Randomized Trial in Uganda
}

\author{
Slawa Rokicki, ${ }^{a, b}$ Brian Mwesigwa, ${ }^{c}$ Peter Waiswa, ${ }^{d, e, f}$ Jessica Cohen ${ }^{g}$
}

\section{Key Findings}

- Universal access to modern energy and safe childbirth are global health priorities that are inextricably linked, yet little research has rigorously examined the adoption and effectiveness of solar energy systems in resourceconstrained settings.

- In sub-Saharan Africa, health facilities lack access to reliable light and electricity. We evaluated the implementation and effectiveness of the We Care Solar Suitcase, a complete solar electric system that provides medical lighting and electrical power for charging small medical devices and mobile phones, on the quality of maternal and infant care.

- The intervention was adopted well by health providers, increased facility brightness, and led to modest increases in the quality of maternal care based on clinical observations of deliveries.

- Reliable light is an important driver of timely and adequate health care and may improve providers' ability and timeliness in performing actions needed to reduce the risk of postpartum hemorrhage.

\section{Key Implications}

Ministries of health, development partners, and other health care reform stakeholders should:

- Invest in modern and renewable energy systems for health care facilities.

- Ensure access to reliable energy is included in larger efforts to improve quality of care via systemic changes to health systems.

\footnotetext{
a Rutgers School of Public Health, Piscataway, NJ, USA.

bUniversity College Dublin, Dublin, Ireland.

'Innovations for Poverty Action, Kampala, Uganda.

dMaternal, Newborn and Child Health Centre of Excellence, Makerere University School of Public Health, Kampala, Uganda.

' Global Public Health, Karolinska Institutet, Stockholm, Sweden.

'Busoga Health Forum, Jinja, Uganda.

${ }^{9}$ Harvard T.H. Chan School of Public Health, Boston, MA, USA.

Correspondence to Slawa Rokicki (slawa.rokicki@rutgers.edu).
}

\section{ABSTRACT}

Background: We evaluated the impact of solar light installation in Ugandan maternity facilities on implementation processes, reliability of light, and quality of intrapartum care.

Methods: We conducted a stepped-wedge cluster-randomized trial of the We Care Solar Suitcase, a complete solar electric system providing lighting and power for charging phones and small medical devices, in 30 rural Ugandan maternity facilities with unreliable lighting. Facilities were randomly assigned to receive the intervention in the first or second sequence in a 1:1 ratio. We collected data from June 2018 to April 2019. The intervention was installed in September 2018 (first sequence) and in December 2018 (second sequence). The primary effectiveness outcomes were a 20 -item and a 36 -item index of quality of intrapartum care, a 6-item index of delays in care provision, and the percentage of deliveries with bright light, satisfactory light, and adequate light.

Results: We observed 1,118 births across 30 facilities. The intervention was successfully installed in $100 \%$ of facilities. After installation, the intervention was used in $83 \%$ of nighttime deliveries. Before the intervention, providers on average performed $42 \%$ of essential care actions and accumulated 76 minutes of delays during nighttime deliveries. After installation, quality increased by 4 percentage points $(95 \%$ confidence interval $[\mathrm{Cl}]=1,8)$ and delays in care decreased by 10 minutes $(95 \% \mathrm{Cl}=-16,-3)$, with the largest impacts on infection control, prevention of postpartum hemorrhage, and newborn care practices. One year after the end of the trial, $90 \%$ of facilities had LED lights in operation and $60 \%$ of facilities had all components in operation.

Conclusions: Reliable light is an important driver of timely and adequate health care. Policy makers should invest in renewable energy systems for health facilities; however, even when reliable lighting is present, quality of care may remain low without a broader approach to quality improvements.

\section{BACKGROUND}

R educing maternal and neonatal mortality are global R public health priorities, yet progress on these goals remains intractably slow. The burden of maternal mortality in low-income countries is staggering-if countries could meet the Sustainable Development Goal of 70 maternal deaths per 100,000 live births by 2030, the lives of an estimated 1.6 million mothers would be saved. ${ }^{1}$ With 
dramatic increases in facility-based deliveries over the past 30 years, the major barrier to meeting this target now lies not in increasing access to health facilities, but in improving the quality of care delivered in these facilities. ${ }^{2,3} \mathrm{~A}$ recent analysis found that over half of maternal and neonatal deaths in low-income countries result from poorquality care rather than from nonutilization of care. ${ }^{3}$ High-quality care requires the provision of effective, timely, and safe health services, delivered by a well-trained and motivated workforce, in a facility equipped with essential infrastructure and supplies, functioning health information systems, and good leadership and governance. ${ }^{4}$

One of the major neglected health system challenges to maternal and child health is the lack of access to reliable energy. Reliable light and electricity are critical for nearly all aspects of safe childbirth, including equipment sterilization, infection control, powering essential medical devices, and nighttime examinations and procedures. ${ }^{5,6}$ Lack of reliable light may hinder providers' ability to manage complications and cause them to delay necessary care actions, putting both mother and infant at risk. ${ }^{7}$ Frequent blackouts may also create stressful working conditions for health care workers, generate patient mistrust, and promote inequities in care. ${ }^{8,9}$ Yet a study across 78 lowand middle-income countries (LMICs) found that $59 \%$ of health facilities lack access to reliable electricity. ${ }^{10}$ In sub-Saharan Africa, one-quarter of health facilities have no connection to the electri-

While improved sources of reliable lighting are needed in many health systems in LMICs, there are significant barriers to expanding grid power to unconnected health facilities.

We assess the
extent to which
using the We Care
Solar Suitcase
improves light
brightness using
light sensors and
direct
observations of
light sources.
cal grid; among connected facilities, frequent and prolonged interruptions to power are common. ${ }^{11}$ This crisis has been compounded by the health and economic consequences of the coronavirus disease (COVID-19) pandemic, a time when proper infection control in health facilities is imperative to mitigate the spread of the virus.

The significance of access to affordable, reliable, and modern energy in strengthening health systems has been recognized by the United Nations' Sustainable Energy for All (SEforAll) and United States Agency for International Development (USAID) Powering Health Care initiatives. ${ }^{12}$ While improved sources of reliable lighting are needed in many health systems in LMICs, there are significant barriers to expanding grid power to unconnected health facilities, including the high cost per mile to extend and maintain a grid to remote areas and the strain such extensions would place on already weak and unreliable infrastructure. Moreover, recent experimental evidence on the demand for rural residential grid connections has found low willingness to pay for electrification among residents; however, aligning programs for new grid connections with opportunities for productive use (e.g., developing small businesses) may facilitate a higher willingness to pay. $^{13,14}$

Renewable energy sources such as solar power may provide a clean, efficient, and cost-effective opportunity to increasing access to reliable light and electricity for health facilities in resourceconstrained settings. ${ }^{5}$ However, there are several challenges to the implementation of solar energy systems in rural health facilities. Health care workers may be reluctant to adopt new technology if they do not see an immediate benefit, or they may use it inconsistently or incorrectly. This outcome is a common finding in the implementation of mobile health and electronic health registration systems in LMICs. ${ }^{15-18}$ Poorly designed technology can quickly fall into disrepair, while inadequate maintenance, such as lack of replacement of batteries, can result in disuse. Finally, there is difficulty in sustainability and scale-up. ${ }^{19}$ Evidence is needed on whether adopting and integrating solar energy into rural health facilities (1) is feasible, (2) improves reliability and brightness of light, and (3) affects quality of care. Most prior quantitative studies examining the relationship between reliable light and health care quality are observational and are subject to unobserved confounding related to patient, provider, and facility factors. As far as we are aware, the only randomized trials evaluating the impact of providing electricity or light on health outcomes in LMICs have included electricity upgrades as part of a broader package of infrastructure, training, supervision, and mentoring, complicating any inference about the specific role that electrification and bright light play in quality of care and patient outcomes. $^{20-22}$ Further, detailed data on light and quality of care-for example, through actual observations of light and health care worker actions-are rarely available.

We conducted a stepped-wedge clusterrandomized controlled trial in Uganda to evaluate the impact of implementing the We Care Solar Suitcase, a complete solar electric system that provides medical lighting and electrical power for charging small medical and communication devices. We first examine the implementation of the intervention in health facilities. We then assess the extent to which using the Solar Suitcase improves light brightness using light sensors and direct observations of light sources. Finally, we use clinical observations of care to evaluate the benefit of the solar system across a range of clinical processes, including the provision of adequate care and the timeliness of care received. 


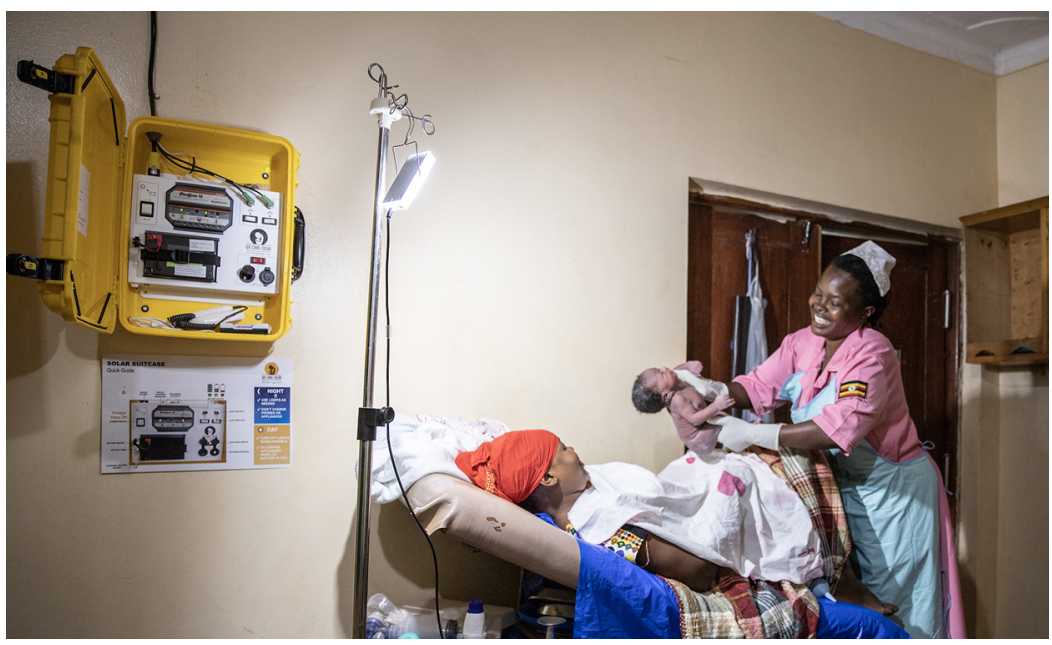

Asiat Musenze, a Ugandan midwife, attends to a mother and her newborn with the light of the Solar Suitcase. (C) 2018 Zahara Abdul

\section{METHODS}

\section{Study Setting}

The study took place in maternity facilities in Uganda. From 2011-2016, the maternal mortality ratio for Uganda was 336 deaths per 100,000 live births, while the perinatal mortality rate was 38 deaths per 1,000 pregnancies. ${ }^{23,24}$ In 2016, $73 \%$ of deliveries in Uganda occurred in a health facility. ${ }^{23}$

Uganda's health sector hierarchy includes national and regional hospitals, followed by a district health system composed of health centers of levels II through IV. These health centers generally staff low- and mid-level providers who provide care for uncomplicated deliveries.

\section{Study Design}

The study design was a stepped-wedge clusterrandomized controlled trial as a staggered rollout of the intervention was necessary owing to limited resources. Facilities were randomized into 1 of 2 sequences, with the first sequence receiving the intervention between the first and second periods of data collection, and the second sequence receiving the intervention between the second and third periods of data collection (Supplement Figure 1). Details of the study methods have been published in the study protocol. ${ }^{25}$

\section{Participants}

Clusters were primary health facilities in the Central, Eastern, and Western regions of Uganda.
We conducted a census of all primary health facilities offering delivery services in these regions. We then excluded facilities that did not meet the inclusion criteria. Details of inclusion and exclusion criteria are specified in Supplement Table 1. In brief, criteria for facilities were (1) level II, III, or IV; (2) open 24 hours a day; (3) the presence of unreliable overhead light; (4) no automatic referral of women elsewhere during blackouts; and (5) willingness of the medical officer in-charge to participate. All health care workers that worked in the maternity ward at these facilities were eligible for interview and observation. Pregnant women aged 16 and older who were admitted to the facilities for labor and delivery and provided written informed consent were eligible to participate.

\section{Randomization}

Randomization of facilities was conducted using Stata's randomize command, with stratification by geographic cluster and a measure of baseline light availability. The randomization that achieved the best balance based on baseline quality of care and facility volume was chosen (Supplement Table 2 has details on stratification and balancing variables). The allocation sequence was generated by the study investigators. Due to the nature of the intervention, neither participants nor researchers were blinded to allocation.

\section{Ethical Approval}

The study was approved by Institutional Review Boards at the Harvard T. H. Chan School of Public 
Health, the Mildmay Uganda Research Ethics Committee, and the Uganda National Council for Science and Technology. Written informed consent was obtained from the facility in-charge or head, all maternal care providers, and all women older than 16 years of age that presented for normal deliveries at facilities.

\section{Intervention}

The intervention was the We Care Solar Suitcase, a complete solar electric system that provides medical lighting and electrical power for charging phones and small medical devices. The system contains a photovoltaic solar panel installed on the roof of a health facility; a 12-V lithium ferrous phosphate battery; high-efficiency, moveable light-emitting diode (LED) lights for maternity rooms; and 2 rechargeable LED headlamps. In addition, it contains a fetal Doppler with rechargeable batteries, 2 12-V DC accessory sockets, 2 USB ports for charging cell phones, and an AA/AAA battery charger. Installations were conducted by a local solar contracting firm based in Uganda. One Solar Suitcase was installed in each facility, with 2-4 overhead LED lights for each delivery room, depending on its size. The product specifications for the Solar Suitcase are open source and technical details are provided in the Supplement Figure 2 (version 2.0) and Figure 3 (version 3.0). Version 2.0 was used in this study. The cost of building a Solar Suitcase, including parts and manufacturing, is US\$2,220 (2018 value). If parts wear out or break down, We Care Solar works with implementation partners, government partners, and on-the-ground staff to identify appropriate incountry recycling and disposal facilities.

To ensure consistent and appropriate use of the installed Solar Suitcase, installers conducted trainings with health care workers on how to use and maintain it and all of its accessories on the day of installation and in subsequent check-ins, as needed. The cost of installation and training is US \$250 per Solar Suitcase.

Data collection began in June 2018 and was completed in April 2019. The intervention was installed in September 2018 (first sequence) and in December 2018 (second sequence).

\section{Data Collection}

Quality of care was measured with direct clinical observations of deliveries using an extensive clinical observation tool adapted from the Maternal and Child Health Integrated Program (MCHIP) Quality of Care Surveys. ${ }^{26}$ Using this observation tool, enumerators indicated whether items that are essential for high-quality care were provided during labor, delivery, and the early postpartum period. Enumerators observed and recorded the care delivered by providers during labor and delivery over 4 stages: arrival and first examination, first stage of labor, second and third stages of labor, and the first hour postpartum. For each item in the observation tool, enumerators recorded whether the item was completed by a health care worker and, if it was completed, recorded a timestamp as to when the item was completed. In addition, enumerators indicated the sources and brightness of light at each of the 4 stages of the observation. The brightness was recorded as "very bright," "somewhat bright," "dim," and "pitch black." Definitions for the level of brightness for these categories are provided in Supplement Table 3; enumerators were trained to interpret these categories uniformly according to these definitions. Finally, after an observation was complete, enumerators reviewed the patient's chart to retrieve information on patient age, parity, and gestational age.

To reduce disruption and influence, enumerators were trained to avoid interaction with providers and patients. Enumerators were provided with digital watches for recording timestamps. To maximize interrater reliability, enumerators were extensively trained on the definition of each item in the observation checklist under the leadership of the study obstetrician. Details on enumerator protocol and interrater reliability are provided in Supplement Table 2.

Data collection was conducted on paper questionnaires, then inputted electronically using double data entry. A Stata user-written code file was used to identify discrepancies between entries, which were resolved by the project manager by referring to the original paper questionnaire and/or by contacting the enumerator. Data management procedures were in place to ensure data quality, including daily checks by the project manager on incoming data to identify data outliers, logical inconsistencies, and missing data.

At the end of each data collection period, enumerators conducted provider interviews to record information on provider demographics, work experience, training, and attitudes. Enumerators also conducted facility assessments with the medical officer in charge to record information on facility staff, monthly patient volume, and electricity interruptions.

Finally, light sensors were installed (HOBO 4-Channel Analog data logger) in the delivery rooms 
of each facility that recorded the light (measured in lux) at each minute for the duration of the study.

Data collection tools were piloted at 5 facilities before study rollout to ensure usability, clarity, and inter-enumerator reliability. Light sensors were also piloted to ensure correct implementation procedures and data usability. Data from these pilot facilities were not included in the final sample.

\section{Implementation Outcomes}

We applied the RE-AIM framework to guide evaluation of implementation outcomes. ${ }^{27}$ We assessed the reach of the intervention by examining the percentage of eligible facilities that participated in the study, as well as the representativeness of study facilities and women delivering in facilities by comparing facility and participant descriptive characteristics with national-level estimates. We examined the implementation of the intervention by determining the percentage of facilities with successful installations and the percentage of health care workers successfully trained. We examined adoption via enumerator-reported main source of light used during the delivery observation before and after implementation of the Solar Suitcase. Sources of light included the Solar Suitcase, electrical grid, other overhead solar light, generator, kerosene lamp, flashlight, and daylight. We also examined whether health care workers self-reported that they felt comfortable using the components of the Solar Suitcase (binary measure) and how often they reported using the various components (lights, headlamp, and fetal Doppler) on a 5-point Likert scale. We examined maintenance by the percentage of facilities with Solar Suitcase components still in operation at 3 post-trial follow-up visits, ranging from 5 months to 1 year after the completion of the trial.

\section{Effectiveness Outcomes}

The primary effectiveness outcomes pre-registered on ClinicalTrials.gov include measures of light, quality of care, and health care worker satisfaction. This article reports on the light and quality of care outcomes. Health care worker outcomes will be reported in a separate paper.

We examined changes in reliability and brightness of light in several ways. We constructed a binary variable for "bright light," which was equal to 1 if the room was "very bright" or "somewhat bright" throughout the entire labor and delivery observation and 0 if the room was "pitch black" or "dim" at any point during observation. The rationale for this breakpoint was that providers were not able to adequately provide care in conditions that were dim or pitch black, according to the definitions for these categories. We also constructed a binary variable for a "satisfactory light source," which was equal to 1 if, throughout the entire observation, one of the following overhead sources was used: Solar Suitcase, electrical grid, other overhead solar light, generator, or daylight. This variable was equal to 0 if any of the following light sources were used during the observation: kerosene lamp, candle, flashlight, solar lamp, or no light at all. The satisfactory sources of light were defined as overhead lights that light the entire room, as opposed to ground-level lights that must be moved to see different areas of the room and only light a small area. The rationale was that moving and holding a light source is dangerous as it occupies and contaminates a health care worker's hands; moreover, unsatisfactory sources such as kerosene lamps and candles are fire hazards and contribute to indoor air pollution. We also combined the source and brightness of the light into a variable indicating "adequate light," which was defined as a binary variable equal to 1 if the light was from a satisfactory source and was "bright" ("very bright" or "somewhat bright") for the duration of observation.

Finally, light sensors were used to measure the number of minutes of light and the level of brightness during the day and night (details on light measures are provided in Supplement Table 3).

Quality of care was measured via enumerator Quality of care observation by extracting 2 indices of quality and 1 index of delays in care from the extended MCHIP observation tool. First, we used a 20 -item quality of care index developed for and validated in low- and middle-income settings. ${ }^{28}$ The index is composed of 20 indicators representing essential components of the process quality of intrapartum and immediate postpartum care in facility deliveries, between the initial patient assessment and first hour postpartum (Supplement Table 4 has individual items). Second, we extended this index to include an additional 16 items to create a 36-item index, with additional items adapted from the MCHIP tool. ${ }^{26}$ The longer index captures additional items that may be particularly affected by the Solar Suitcase, such as checking the fetal heart rate and disposal of waste. Both indices were constructed as the percentage of total items performed per delivery observation and thus range from $0 \%$ to $100 \%$. We also calculated section indices across areas of (1) history taking/communication, (2) patient assessment, (3) infection control, (4) prevention of postpartum hemorrhage, and (5) newborn care.

\section{was measured via enumerator observation, using 2 indices of quality and 1 index of delays in care from the extended MCHIP observation tool.}


Lastly, we constructed a "delays in care" index, capturing items that occur throughout the delivery process, including time between facility arrival and first contact with health care worker, time between facility arrival and first vaginal examination, time between delivery and provision of uterotonic, time between delivery and assessment of perineal and vaginal lacerations, time between delivery and drying baby with towel, and time between delivery and initiation of breastfeeding. Measurements and definitions of outcomes are provided in more detail in Supplement Table 3.

\section{Statistical Analysis}

Results from baseline (period 1) were used to provide initial estimates on power and sample size. Sample size calculations were conducted using the stepped-wedge function in Stata v15. We estimated the detectable effect sizes assuming 22 births per facility (average cluster size) for 2 steps, 13 clusters randomized at each step, $80 \%$ power, and $\alpha=0.05$. We assumed, conservatively, that $61 \%$ of deliveries before the intervention would be conducted without adequate light, with an intracluster correlation (ICC) of 0.20. Our minimum detectable effect size for adequate light was 13 percentage points. For quality, we assumed an average pre-intervention score of $44 \%$, with an ICC of 0.4. Our minimum detectable effect size based on these conservative estimates was 11 percentage points. In practice, our observed cluster size was 38 births per facility, which led to a larger detectable effect size than estimated in power calculations.

We first conducted an analysis of the causal effect of the intervention on outcomes using linear regression models with facility fixed effects. The parameter of interest was the coefficient on an indicator for whether the observation occurred in a facility that had been randomized to receive the Solar Suitcase installed at the time of observation or not. To account for the varying amount of time spent observing at each facility (due to differences in patient volume and availability of light), models were also adjusted for the duration of time spent in facilities (measured by the number of enumerator shifts worked at each facility in each period). Standard errors were clustered at the facility level.

We analyzed all observations as well as the subset of observations in which at least some part of the observation occurred during the nighttime hours of 6:00 pm to 7:00 am. Our rationale was that, while clinical care provided during nighttime hours would likely be the most directly affected by the adequacy of light, facility lighting may be dim and could benefit from brighter light even in daytime hours.

In our analysis, we first present the sources of light used to conduct deliveries during nighttime hours $(6: 00 \mathrm{pm}$ to 7:00 am) before and after the intervention, presenting the light source at the time the newborn was delivered. We next present the impact of the intervention visually, plotting linear predicted values over period and sequence from the regression models described above. Finally, we present regression results.

\section{Sensitivity Analysis}

We conducted several sensitivity analyses, including alternate specifications, adjustment of standard errors using the wild cluster bootstrap method, ${ }^{29,30}$ imputation of missing data, assessment of enumerator bias or Hawthorne effects, ${ }^{31}$ assessment of whether there was selection of providers or patients into better lit facilities after implementation, and the inclusion of observations that resulted in a multiple birth, stillbirth, or infant death (Supplement Table 5 includes methodological details of sensitivity analyses).

\section{Patient and Public Involvement}

This research was done with guidance from of the Uganda Ministry of Health, Directorate of Clinical Services, which provided authorization to conduct the research in particular districts, as well as input into health facility selection. At a district level, input on facility selection and support for the study were provided by district health officers. Results will be disseminated to the Ministry of Health.

\section{RESULTS}

\section{Reach}

All facilities that met the inclusion criteria agreed to participate in the study and all health care workers within these facilities eligible for participation also agreed to participate (Figure 1). Facilities included in the study were similar to primary-level facilities in Uganda. In the most recent nationally representative survey of health facilities in Uganda (2013), 84\% of primary facilities offer 24-hour facility-based delivery services and $51 \%$ have unreliable electricity. ${ }^{32}$

Between June 2018 and April 2019, 1,183 patients arrived at study facilities to deliver. Of these, 59 were excluded at arrival, with the most common reason being that the patient arrived in the active stage of labor so that written consent was not 
FIGURE 1. Consort Diagram of Maternal Health Care Facilities in Uganda Included in the Solar Suitcase Intervention Study

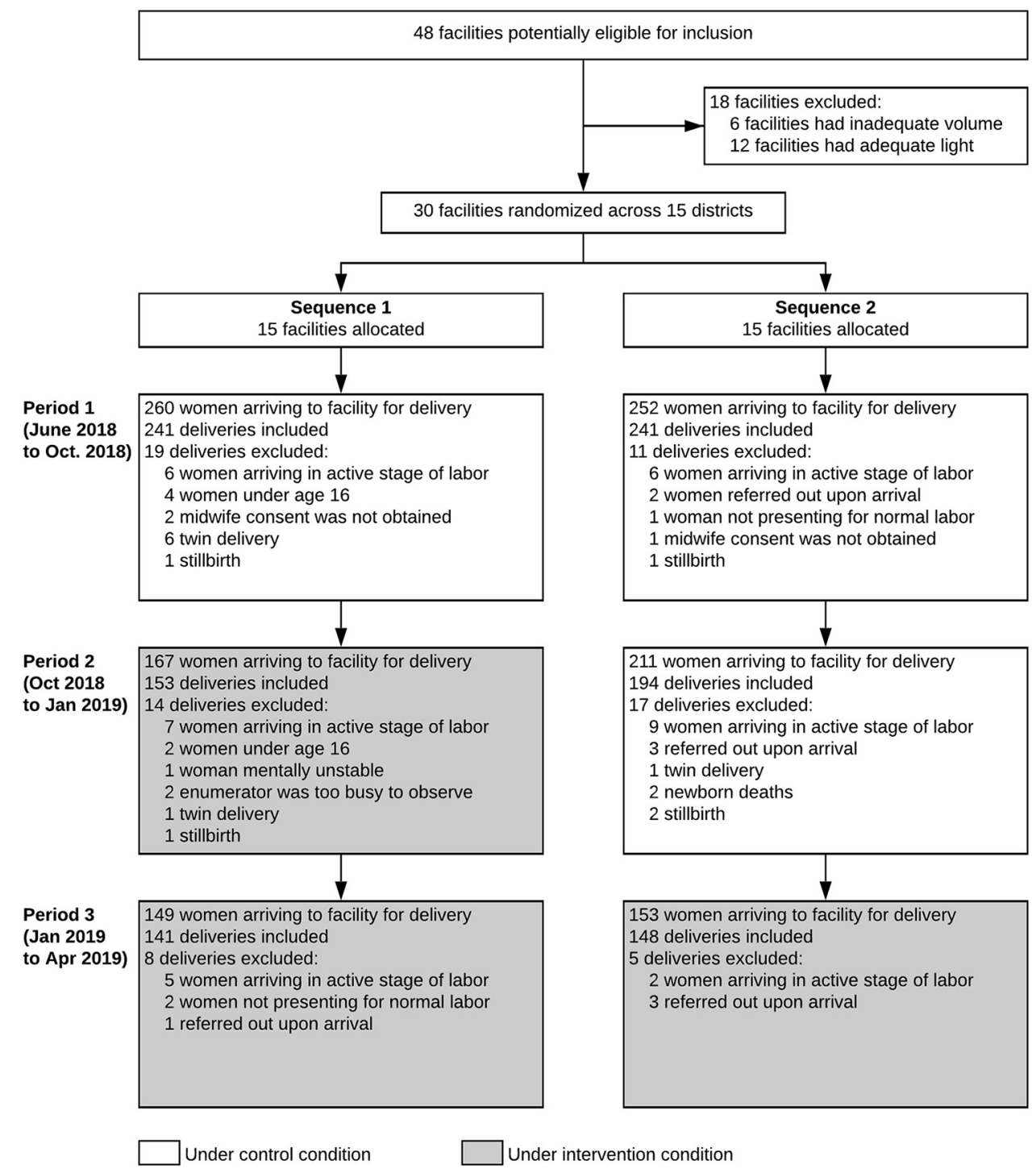

possible to obtain before delivery. Additionally, we excluded 8 observations that were twin deliveries, 2 that resulted in a newborn death, and 5 that resulted in a stillbirth. The final sample size was 1,118 birth observations.

Table 1 shows pre-intervention characteristics of facilities, providers, and patients, as well as tests for balance in these characteristics across the facilities randomized to receive the intervention first (sequence 1) and the facilities randomized to receive the intervention second (sequence 2 ). No systematic evidence of imbalance was apparent, with the $P$-value for the $F$-test on joint equality equal to 0.24 . The mean number of staff present was 7 in our sample, compared with 8 in the national survey sample of primary-level facilities. ${ }^{33}$ On staff, we observed more midwives/nurses $(70 \%)$ than clinical officers (15\%) and nursing assistants (15\%), compared with $44 \%$ midwives/ nurses, $13 \%$ clinical officers, and $44 \%$ nursing 
TABLE 1. Baseline Characteristics of Maternity Health Care Facilities in Uganda $(\mathrm{N}=30)^{a}$ Included in the Study of the Solar Suitcase Intervention on the Quality of Intrapartum Care

\begin{tabular}{|c|c|c|c|}
\hline & $\begin{array}{l}\text { Overall } \\
\mathrm{N}=30\end{array}$ & $\begin{array}{c}\text { Sequence } 1 \\
n=15\end{array}$ & $\begin{array}{c}\text { Sequence } 2 \\
n=15\end{array}$ \\
\hline No. of observations per facility, mean (SD) & $38(16)$ & $36(19)$ & $39(14)$ \\
\hline No. of days spent observing, mean (SD) & $30(12)$ & $30(12)$ & $30(12)$ \\
\hline No. of MCH staff employed, mean (SD) & $7(4)$ & $6(3)$ & $8(5)$ \\
\hline Monthly patient volume, mean (SD) & $34(17)$ & $30(18)$ & $37(16)$ \\
\hline \multicolumn{4}{|l|}{ Primary source of electricity, $n(\%)$} \\
\hline None/lanterns & $12(40)$ & $6(40)$ & $6(40)$ \\
\hline Grid & $11(37)$ & $5(33)$ & $6(40)$ \\
\hline Solar & $7(23)$ & $4(27)$ & $3(20)$ \\
\hline Facility government owned, $n(\%)$ & $28(93)$ & $13(87)$ & $15(100)$ \\
\hline \multicolumn{4}{|l|}{ Facility level, n (\%) } \\
\hline Health center II & $5(17)$ & $3(20)$ & $2(13)$ \\
\hline Health center III & $22(73)$ & $11(73)$ & $11(73)$ \\
\hline Health center IV & $3(10)$ & $1(7)$ & $2(13)$ \\
\hline Provider age, mean (SD) & $34(5)$ & $33(5)$ & $35(6)$ \\
\hline Provider years of experience, mean (SD) & $8(6)$ & $7(5)$ & $9(7)$ \\
\hline Proportion of providers with secondary education, mean (SD) & $0.02(0.07)$ & $0.04(0.10)$ & $0.00(0.00)$ \\
\hline Proportion of providers with certificate, mean (SD) & $0.60(0.32)$ & $0.62(0.35)$ & $0.58(0.31)$ \\
\hline Proportion of providers with diploma, mean (SD) & $0.38(0.32)$ & $0.34(0.34)$ & $0.42(0.31)$ \\
\hline Proportion of providers in officer position, mean (SD) & $0.15(0.22)$ & $0.15(0.22)$ & $0.16(0.22)$ \\
\hline Proportion of providers in midwife/nurse position, mean (SD) & $0.70(0.26)$ & $0.61(0.28)$ & $0.79(0.23)$ \\
\hline Proportion of providers in nursing assistant position, mean (SD) & $0.15(0.22)$ & $0.24(0.26)$ & $0.06(0.12)$ \\
\hline Quality score, mean (SD) & $44.2(8.4)$ & $43.5(7.9)$ & $45.0(9.0)$ \\
\hline Delay index score (minutes), mean (SD) & $73.5(16.9)$ & $76.4(19.4)$ & $70.7(14.1)$ \\
\hline Proportion of adequate light throughout observation, mean (SD) & $0.44(0.21)$ & $0.47(0.22)$ & $0.41(0.20)$ \\
\hline Mother's age (years), mean (SD) & $24.5(2.5)$ & $25.0(2.8)$ & $24.1(2.1)$ \\
\hline Mother's parity, mean (SD) & $2.3(0.6)$ & $2.3(0.5)$ & $2.3(0.7)$ \\
\hline Gestational age (weeks), mean (SD) & $38.1(0.9)$ & $38.0(0.9)$ & $38.1(0.9)$ \\
\hline Overall F-test & 0.24 & & \\
\hline
\end{tabular}

Abbreviations: $\mathrm{MCH}$, maternal and child health; $\mathrm{SD}$, standard deviation.

a The overall F-test is a joint test of orthogonality of all variables. Quality score is the percentage of items performed of the 20-item index. Delay index score is the sum of 6 items in the delays index (Supplement Table 3).

assistants in the national survey. Facilities in the sample also experienced higher patient volume (34 average deliveries per month) compared with the national sample (14 average deliveries per month). Women delivering were an average of 24.5 years old, with a parity of 2.3 , and an average gestational period of 38.1 weeks. In comparison, a national sample of pregnant women in Uganda had an average age of 25.8, with a parity of $1.2 .^{23}$ 


\section{Implementation and Adoption}

Over the course of the trial, the Solar Suitcase intervention was successfully installed in $100 \%$ of facilities, with $76 \%$ of health care workers trained on its use by the contractor and another $13 \%$ trained by another health care worker in the facility. Figure 2 shows adoption of the Solar Suitcase into the health facilities by examining sources of light used to conduct deliveries during nighttime hours $(6: 00 \mathrm{pm}$ to 7:00 am) before and after the intervention, as measured by direct observation. Across all deliveries that occurred during nighttime hours $(n=571)$, there were 690 light sources used; $20 \%$ of deliveries used more than 1 light source. Before the intervention, $44 \%$ of these light sources used were either a kerosene lamp or flashlight, compared with $0 \%$ of light sources used after the intervention was deployed. After it was deployed, the Solar Suitcase was used in $83 \%$ of all nighttime deliveries and made up $65 \%$ of all light sources used.

Health care workers' self-reported use of the Solar Suitcase was consistent with the results from direct observation shown in Figure 2. Ninety percent of health care workers agreed that they felt comfortable using the Solar Suitcase and $88 \%$ of health care workers used the Solar Suitcase LED lights for most or every nighttime delivery, although less than $10 \%$ of health care workers used the Solar Suitcase lights during the day. Use of the headlamp and fetal Doppler components were less consistent: $56 \%$ of health care workers never or rarely used the headlamp, while $29 \%$ never or rarely used the fetal Doppler (Supplement Table 6).

\section{Effectiveness}

Figure 3 presents the graphic representation of the impact of the intervention on measures of adequate light and quality of care. The figure demonstrates that sequence balance was achieved in period 1 for both adequate light and quality outcomes. While the proportion of all deliveries with adequate light was the same across sequences in period 1 at $56 \%$, this proportion increased to $100 \%$ in period 2 for facilities in sequence 1 , while it remained stagnant for facilities in sequence 2 . In period 3, both sequences indicated $100 \%$ of deliveries were conducted with adequate light. The results on quality have a similar trapezoidal shape in the figure, providing strong evidence that the changes in outcomes can be attributed to the intervention.

We formalize this descriptive analysis with the results of the regression models (Table 2). Before the intervention, $56.1 \%$ of all observed deliveries (42.4\% of deliveries with some nighttime hours) were conducted with bright light and $66.3 \%$ of all deliveries $(55.7 \%$ of deliveries with some nighttime hours) were conducted with a satisfactory light source (Table 2). Similarly, $54.4 \%$ of deliveries were conducted with adequate light $(41.0 \%$ of deliveries with some nighttime hours). The intervention had a

\author{
The Solar Suitcase \\ was successfully \\ installed in \\ $100 \%$ of facilities, \\ with $\mathbf{8 9} \%$ of facility \\ health care \\ workers receiving \\ training on its use.
}

FIGURE 2. Source of Light During the Delivery of Infant, in Periods When Facilities Had a Solar Suitcase Compared With Periods When Facilities Did Not Have a Solar Suitcase, Among Observations in Which Birth Occurred During Nighttime Hours ${ }^{a}$

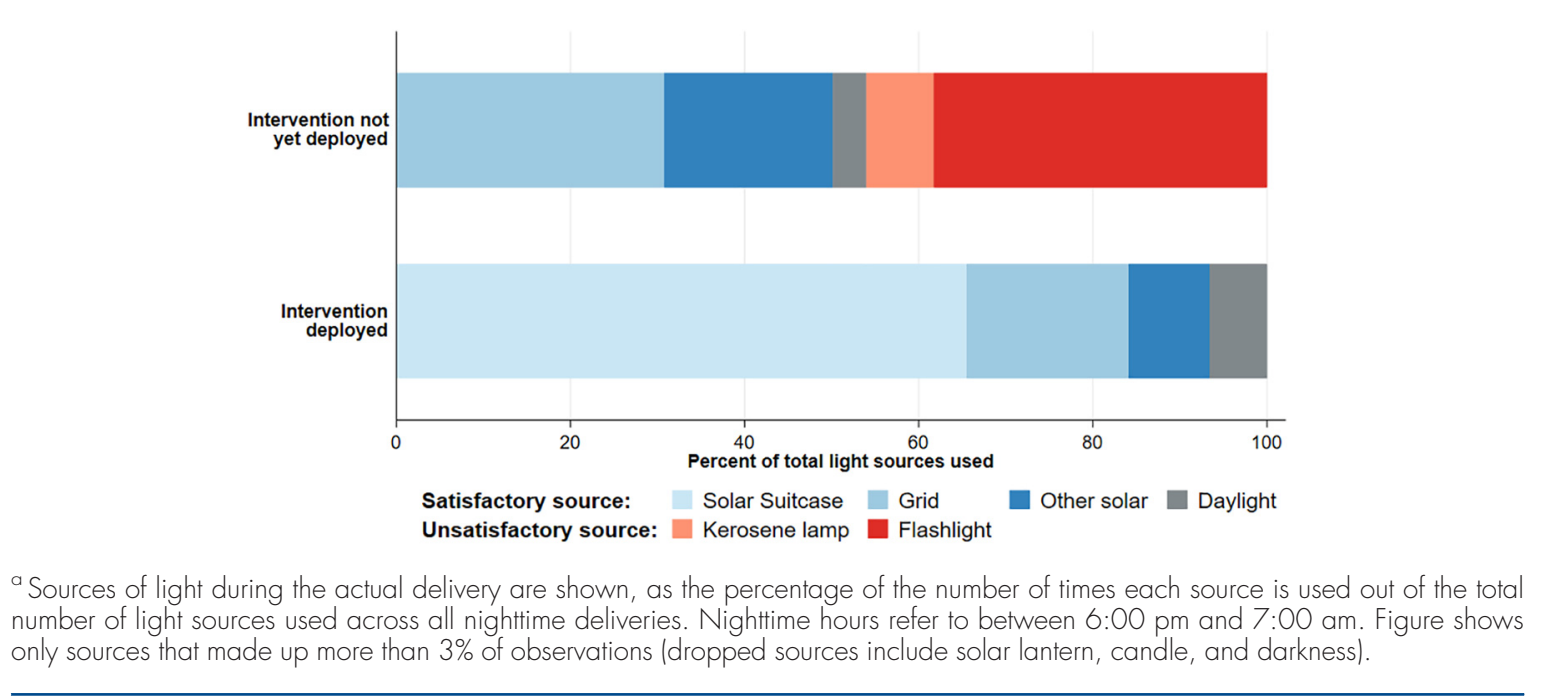


FIGURE 3. Impact of Solar Suitcase Intervention on Adequacy of Light and the 20-Item Quality of Care Index, for all Observed Deliveries $(n=1,118)$ and for Observed Deliveries With Some Nighttime Hours $(n=743)$ in Maternal Health Care Facilities in Uganda ${ }^{a}$
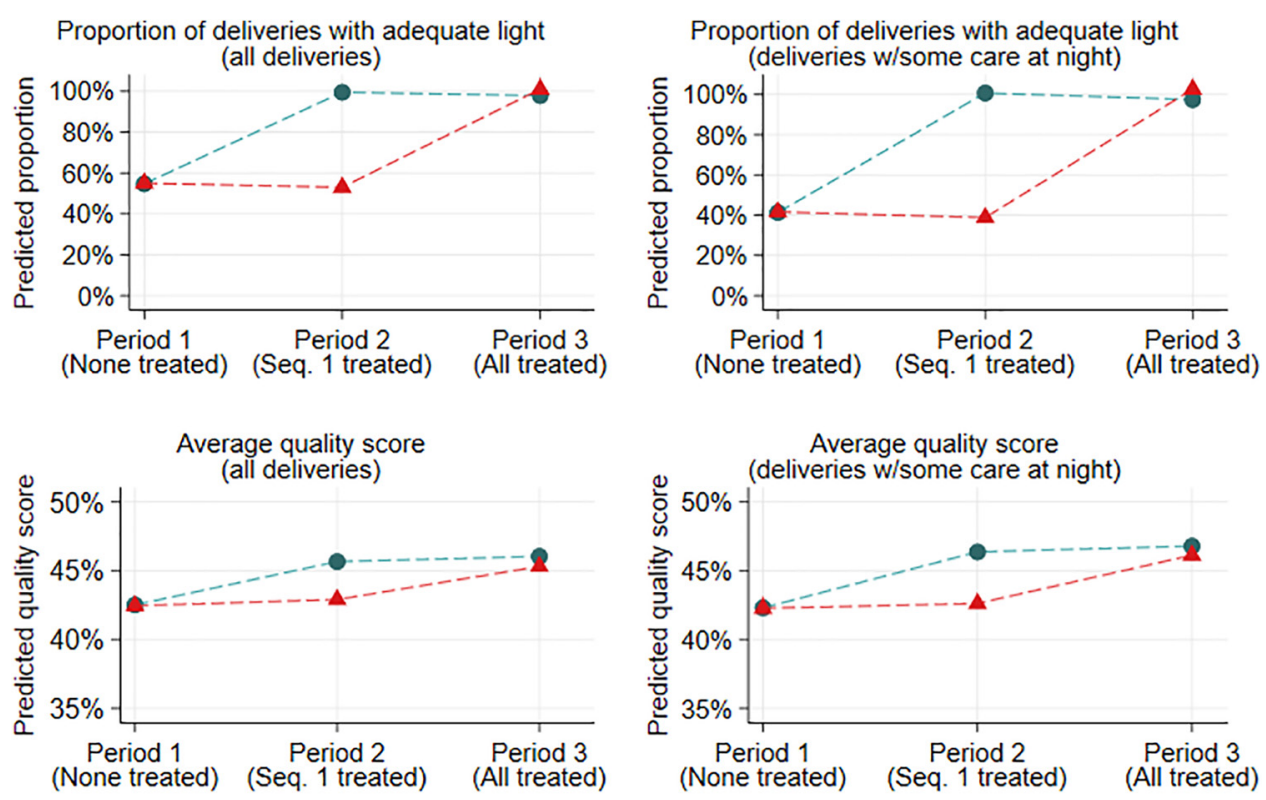

----- Sequence $1 \quad---1--$ Sequence 2

a "Adequate light" indicates that all observed parts of observation were perceived to be under a bright light and from a satisfactory light source. Quality score is the percentage of items performed of the 20-item Tripathi index. Supplement Table 3 has detailed definitions of variables. Results from predicted margins of linear regression with facility fixed effects. Nightilime hours refers to between 6:00 pm and 7:00 am.

After the
intervention,
$100 \%$ of all
deliveries and
nighttime
deliveries were
conducted with a
bright, satisfactory
light source and
adequate light.

large and significant impact on all light measures, increasing the proportion of all deliveries conducted with bright light by 43.7 percentage points $(95 \% \mathrm{CI}=35.9,51.5)$, the proportion with a satisfactory light source by 33.3 percentage points (95\% CI=27.2, 39.4), and the proportion with adequate light by 45 percentage points $(95 \% \mathrm{CI}=$ $37.2,52.8)$. Estimates were larger for the subset of deliveries with some nighttime hours. These results indicate that after the intervention, $100 \%$ of all deliveries and nighttime deliveries were conducted with a bright, satisfactory light source and adequate light. The calculated ICCs were generally lower than assumed.

Results of the analysis of sensor data were consistent with enumerator-reported outcomes on light (Table 3). The intervention significantly increased the number of daily minutes of light by 141 minutes (95\% CI=7.6, 274.3), from 856 minutes to 997 minutes. While the level of brightness was not significantly affected by the intervention during the daytime hours, the level increased by
10.1 percentage points $(0.71,19.6)$ during nighttime hours, from 14.5 to 24.7 .

Regarding results on quality of care, among all observed deliveries, the average pre-intervention quality score was $42.6 \%$ for the 20 -item index and $53.9 \%$ for the 36-item index (Table 2). Deployment of the intervention increased the 20 -item quality index by 3.1 percentage points $(95 \% \mathrm{CI}=-0.04,6.2)$ to $45.7 \%$, and the 36 -item index by 4.2 percentage points $(95 \% \mathrm{CI}=1.47,6.98)$ to $58.1 \%$. Results for the subset of observations with some nighttime hours were slightly larger (4.1 and 4.7 percentage points for the 20 -item and 36 -item indices, respectively). Among all observations, delays in care were reduced by 11.24 minutes (95\% CI $=-16.47,-6.01)$, from an average of 74.3 minutes before the intervention to 63.1 minutes after the intervention. Similar results on delays in care were found for the subset of observations with some nighttime hours (-9.67 minutes [95\% CI $=-16.06,-3.29])$. Estimates of the impact of the intervention on 
TABLE 2. Linear Estimates of the Impact of the Solar Suitcase Intervention on Light and Quality of Intrapartum Care $^{a}$ in Maternal Health Care Facilities in Uganda

\begin{tabular}{|c|c|c|c|c|c|}
\hline Outcome & $\mathbf{N}$ & ICC & $\begin{array}{l}\text { Average before } \\
\text { intervention, \% }\end{array}$ & $\begin{array}{l}\text { Average after } \\
\text { intervention, } \%\end{array}$ & $\begin{array}{l}\text { Difference, \% } \\
(95 \% \mathrm{Cl})\end{array}$ \\
\hline \multicolumn{6}{|l|}{ All observed deliveries } \\
\hline \multicolumn{6}{|l|}{ I. Light brightness and source } \\
\hline Deliveries with bright light & 1,118 & 0.07 & 56.1 & 100 & $43.7(35.9,51.5)$ \\
\hline Deliveries with satisfactory light source & 1,118 & 0.07 & 66.3 & 100 & $33.3(27.2,39.4)$ \\
\hline Deliveries with adequate light & 1,118 & 0.07 & 54.4 & 99.4 & $45(37.2,52.8)$ \\
\hline \multicolumn{6}{|l|}{ II. Quality of care } \\
\hline 20-item quality index & 1,118 & 0.21 & 42.6 & 45.7 & $3.1(-0.04,6.24)$ \\
\hline 36-item quality index & 1,118 & 0.21 & 53.9 & 58.1 & $4.2(1.47,6.98)$ \\
\hline 6-item delays index, $\min$ & 805 & 0.12 & 74.3 & 63.1 & $-11.24(-16.47,-6.01)$ \\
\hline \multicolumn{6}{|l|}{ Observed deliveries with some nighttime hours } \\
\hline \multicolumn{6}{|l|}{ I. Light brightness and source } \\
\hline Deliveries with bright light & 743 & 0.14 & 42.4 & 100 & $57.5(46.0,69.1)$ \\
\hline Deliveries with satisfactory light source & 743 & 0.17 & 55.7 & 100 & $44.7(35.4,53.9)$ \\
\hline Deliveries with adequate light & 743 & 0.14 & 41.0 & 100 & $59(47.6,70.4)$ \\
\hline \multicolumn{6}{|l|}{ II. Quality of care } \\
\hline 20-item quality index & 743 & 0.22 & 42.3 & 46.5 & $4.1(0.57,7.68)$ \\
\hline 36-item quality index & 743 & 0.22 & 53.9 & 58.5 & $4.7(1.58,7.78)$ \\
\hline 6-item delays index, minutes & 575 & 0.13 & 76.0 & 66.3 & $-9.67(-16.06,-3.29)$ \\
\hline
\end{tabular}

Abbreviations: $95 \% \mathrm{Cl}$, 95\% confidence interval; ICC, intracluster correlation.

a Results show point estimates and $95 \%$ confidence intervals. Standard errors are clustered at the facility level. The constant refers to the mean outcome in the preperiod. Nighttime hours refer to hours between 6:00 pm to 7:00 pm. Bright light indicates enumerator reported "perfectly bright" or "bright" (as opposed to "dim" or "dark") across all 4 sections of the observation. Satisfactory light source indicates that the light source during all 4 sections was either daylight, the grid, solar, or a generator. Adequate light indicates that all 4 sections of the observations used a satisfactory light source and were reported to be bright. Quality of care indices are defined in Supplement

Table 3. Delays index is missing for observations in which any one of the 6 delays items is missing.

individual delay index items are shown in Supplement Table 7, with the largest effects on reducing time from arrival to first interaction and time from delivery to initiating breastfeeding.

Figure 4 shows the results of the impact of the intervention on individual items of the 20 -item and 36-item indices and section indices. Point estimates and confidence intervals are shown in Supplement Table 8. The largest impacts of the intervention were found in infection control (8 percentage point increase [l to 15]), prevention of postpartum hemorrhage (6 percentage point increase [2 to 10]), and newborn care (5 percentage point increase [0 to 10]). In terms of individual items, the intervention had the most significant impact on checking fetal heart rate, sterilization of equipment (usually conducted chemically with chlorine or chlorhexidine), preparing cord clamps for delivery, assessing completeness of the placenta, applying traction to the cord, checking for tears, and washing hands after clean-up. Health care workers also used the fetal Doppler that was included as part of the Solar Suitcase intervention. In nearly $40 \%$ of observed deliveries, health care workers used the Doppler to measure fetal heart rate after the intervention was deployed. While pairwise $P$-values indicated a significant impact of the intervention on individual items within these care domains, adjusting for multiple hypothesis testing within domains resulted in few significant results at the .05 level.

Sensitivity analyses produced similar results to the main analysis (Supplement Table 9-13).

\author{
The largest \\ impacts of the \\ intervention were \\ found in infection \\ control, \\ prevention of \\ postpartum \\ hemorrhage, and \\ newborn care.
}


TABLE 3. Linear Estimates of the Impact of the Solar Suitcase Intervention in Maternal Health Care Facilities in Uganda on Objective Measures of Light Using Sensor Data ${ }^{a}$

\begin{tabular}{lccr}
\hline Outcome & $\begin{array}{c}\text { Average Before } \\
\text { Intervention }\end{array}$ & $\begin{array}{c}\text { Average After } \\
\text { Intervention }\end{array}$ & Difference (95\% Cl) \\
\hline Minutes of light per 24 hours & 856 & 997 & $141.0(7.6,274.3)$ \\
\hline Level of brightness during daytime $(7: 00 \mathrm{am}$ to $6: 00 \mathrm{pm})$ & 47.9 & 54.2 & $6.3(-2.2,14.8)$ \\
\hline Level of brightness during nighttime $(6: 00 \mathrm{pm}$ to $7: 00 \mathrm{~cm})$ & 14.5 & 24.7 & $10.1(0.71,19.6)$ \\
\hline
\end{tabular}

Abbreviation: $95 \% \mathrm{Cl}, 95 \%$ confidence interval.

a Results show point estimates and 95\% confidence intervals. Standard errors are clustered at the facility level. Regression controls for month of year and facility fixed effects. One facility (in Sequence 2) had a broken sensor and was not included. The number of minutes of light per day is calculated as the number of minutes over a threshold of $20 \%$ of the maximum seen in that facility. Results robust to using any threshold between $1 \%$ and $35 \%$ (results not shown). Level of brightness is on a $0-100$ scale, as the percentage of the maximum light the sensor in each facility could read.

\section{We found that adequate light can significantly reduce the time that passes between a patient's arrival at a facility and their first interaction with a health care provider, which is critical for women with high-risk pregnancies.}

\section{Maintenance}

We examined the percentage of facilities with Solar Suitcase components in operation across 3 posttrial follow-up visits, up to 1 year after the completion of the trial. At 1 year after the end of the trial, $93 \%$ of facilities had the Solar Suitcase LED lights still in use (i.e., functioning and available). The percentage of facilities with the following components still in use 1 year after follow-up were fetal Doppler $(90 \%$ of facilities), headlamps (83\%), and USB ports $(83 \%)$ (Supplement Table 14). The main challenges reported for why components were not in use were that they were malfunctioning, stolen, or missing and that newly arrived health care workers were not trained to use them. Additionally, $27 \%$ of facilities reported that LED lights from the Solar Suitcase, while functioning, did not last through the night or became dim.

\section{DISCUSSION}

The results of this stepped-wedge clusterrandomized trial show that a solar energy system intervention in rural Ugandan maternity facilities was well adopted, increased brightness and adequacy of lighting for maternal and infant care, and led to increases in the quality of care received by women and newborns. While over $40 \%$ of deliveries were conducted by flashlight or kerosene lamp at baseline, receipt of the solar light intervention increased the proportion of deliveries conducted with adequate light to $100 \%$. Deployment of the intervention also increased quality of care, particularly in the areas of infection control, prevention of postpartum hemorrhage, and newborn care, while decreasing delays in the provision of care.
Reports from health care workers confirmed the widespread use of the Solar Suitcase LED lights and USB ports. However, fewer used the associated devices: $56 \%$ of health care workers reported not making use of the headlamps and $30 \%$ reported not using the fetal Doppler. In interviews, a common explanation given from health care workers for the inconsistent use of the Doppler was insufficient gel to use with the device as well as technical difficulties in using it. These results are consistent with World Health Organization research finding that many complex medical devices in low-resource settings do not function as intended. ${ }^{34}$ Regarding maintenance measures, $93 \%$ of facilities reported using the LED lights 1 year after the end of the trial period. However, some challenges to maintained use were identified, with $27 \%$ of facilities reporting that the solar lights did not last through the night or became dim. In the long term, conducting an energy audit with facilities would produce valuable information on a facility's energy usage to tailor the Solar Suitcase or design and install other renewable solutions that meet facility needs. ${ }^{35}$

The introduction of reliable light decreased delays in performance of essential care actions. Delays in care, often referred to as the "third delay" in the 3-delays model of access to delivery care, can result in undiagnosed and untreated complications that increase the risk of maternal mortality and morbidity. ${ }^{36}$ This study found that adequate light can significantly reduce the time that passes between a patient's arrival at a facility and their first interaction with a health care provider, a time that is critically important for women with high-risk pregnancies who need to be triaged or transferred to a higher-level facility. ${ }^{37}$ 
FIGURE 4. Impact of Solar Suitcase Intervention on Individual Quality Items, Section of Care Indices, and Overall Indices, for Observed Deliveries in Maternal Health Care Facilities in Uganda With Some Nighttime Hours $^{a}$

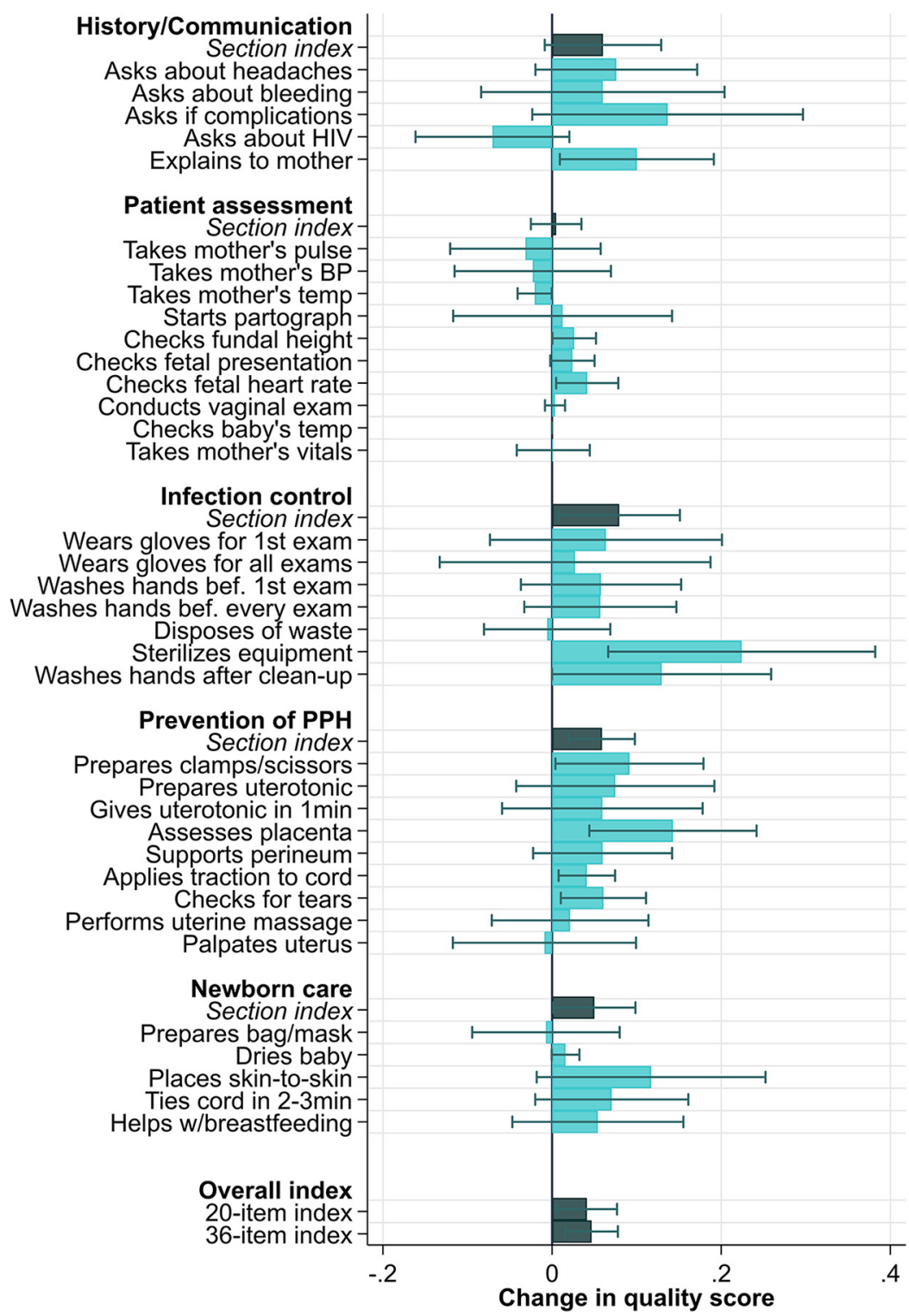

a Results show point estimates and $95 \%$ confidence intervals. Standard errors are clustered at the facility level. Section and overall indices are the proportion of items performed out of the total section and overall total observed, respectively. Linear regression with facility fixed effects and clustered standard errors. Analysis includes only observed deliveries with some nighttime hours. Sterilizes equipment is coded as 1 for observations in which no reusable instruments were used (30\% of observations). BP, blood pressure: $\mathrm{PPH}$, postpartum hemorrhage. Analysis includes only observed deliveries with some nighttime hours (between 6:00 pm and 7:00 am).

Consistent with previous literature on maternal care quality in sub-Saharan Africa, the observed quality of maternity care in this sample of primary care Ugandan facilities was insufficient, with a large number of essential processes of care not provided. ${ }^{38,39}$ Before the intervention was deployed, providers were performing only $42 \%$ of the essential care items for safe deliveries. 
The introduction of adequate light increased this to $46 \%$, including items of known clinical significance such as assessing the completeness of the placenta and checking for lacerations, a 9.5\% increase. The improvement in quality observed in this study is similar to that of other quality improvement interventions in LMICs. An overview of systematic reviews found that the use of reminders to prompt providers to perform actions produced a median relative effect of $14 \%$, while multifaceted interventions produced modest to moderate improvements in professional practice of between $5 \%$ and $20 \% .{ }^{40}$

Overall, the results provide support for the importance of providing all Ugandan maternity facilities with reliable, bright light, but they also indicate that even when facilities have high-quality light, conditions may still be insufficient to ensure safe childbirth. These results underscore recommendations from global heath quality improvement committees that efforts to improve quality must include transformative, systemic changes across all levels of the health system. ${ }^{41,42}$

While the magnitude of the effect sizes on quality is modest, the intervention may have greater impacts in countries where access to reliable light is lower. Moreover, several potential benefits to improved lighting are not captured in this evaluation. For example, women may be more likely to decide to deliver in a well-lit facility and may also be less likely to be referred to higherlevel facilities due to electricity interruptions, which can be dangerous when such facilities are distant and transportation is unreliable. There may also be impacts on health care worker morale and retention, which we will examine in future publications. Overall, given limited resources in LMICs, cost-effectiveness analyses could help clarify priorities for health sector investment in health system strengthening across domains of energy access, medical equipment and supplies, health financing, service delivery, and human resources. ${ }^{43}$

This study has several strengths. We used direct clinical observations of care, which is the gold standard in assessing quality of care. We also used both observations of sources and brightness of light and light sensors to validate our results. Results from the light sensors found that the intervention increased the number of daily minutes of light and the brightness of the room during nighttime hours, corroborating the enumeratorreported results of brightness. Our study design, a stepped-wedge cluster-randomized controlled trial, allowed for observation before and after deployment of the intervention in all facilities and minimized risk of confounders.

\section{Limitations}

This study also has several limitations. First, while direct observation of care is the gold standard in assessing quality, it also has limitations including the possibility that providers change their behavior as a result of being watched (the Hawthorne effect). The possibility also exists that enumerators do not always score the care they observe accurately. In our sensitivity analyses, we did not find strong evidence for either of these effects on the results. Second, the lack of blinding is a limitation. Enumerators may have scored quality of care better when a facility received a Solar Suitcase because they anticipated a positive effect of the intervention. However, the quality metric we used is validated as a reliable, objective measure. Moreover, enumerators were not deployed to the same facilities in all 3 periods. Another possibility is that enumerators record higher or lower scores when there is better light because they can see more clearly. However, the direction of this effect is ambiguous, and we found no evidence of this in our qualitative debriefings with enumerators. Finally, our analysis focused on uncomplicated vaginal deliveries and was not designed or powered for analysis of quality of care during complications. Thus, these results do not speak to any potential impact of better lighting on the management of maternal or newborn complications.

\section{CONCLUSIONS}

Universal access to modern energy sources and safe childbirth are both key sustainable development goals. ${ }^{44}$ Moreover, identifying effective approaches to improving the quality of health care in LMICs is an urgent public health goal. ${ }^{45}$ We find that reliable light is an important driver of timely and adequate health care and may improve providers' ability and timeliness in performing actions needed to reduce the risk of postpartum hemorrhage. Investment in modern and renewable energy systems for health care facilities is a critical priority; our results support recommendations by international organizations such as SEforAll, USAID, and the World Bank to develop guidance on energy access and clinical equipment needs of community-level primary health facilities and to facilitate large-scale facility electrification efforts. ${ }^{12,46,47}$ However, quality of care may remain low even in the presence of reliable light without a broader, systemic approach to high-quality health systems strengthening. 
Acknowledgments: We are grateful to the study participants and our Uganda Ministry of Health partners who devoted their time to this study. From We Care Solar, we thank Brent Moellenberg for advice on installation of and measurement from light sensors and power monitors, Feza Greene for help assessing facility eligibility and obtaining study approvals, and Laura Stachel and Christina Briegleb for extremely valuable input on the study. From Innovations for Poverty Action, we thank Juliana Kayaga for superb guidance on the clinical observations, Juliet Ajilong for excellent field management, Ivan Sengendo for invaluable support in data collection, Ashiraf Mawanda for implementation of the pilot for this project, Laura Schmucker for excellent project management, Damien Kirchhoffer and Jessie Pinchoff for early input into the study design, and Ginger Golub for interim project management. We also gratefully acknowledge our anonymous reviewers. Their helpful comments strengthened this article.

Funding statement: This trial was funded by a grant from the UBS Optimus Foundation to the NGO We Care Solar (WCS), with a contract to conduct an independent evaluation to Innovations for Poverty Action, the Harvard School of Public Health, and University College Dublin. The UBS Optimus Foundation reviewed the trial study design, while WCS reviewed and provided feedback on the trial study design, data collection tools, and manuscript. Neither UBS nor WCS had input on data analysis or interpretation or any authority over the decision to submit the manuscript for publication. SR, BM, and JC had full access to all the data in the study. All authors had final responsibility for the decision to submit for publication.

Author contributions: SR, BM, PW, and JC designed the study. SR, BM and JC developed the protocol and managed implementation and data collection. SR and JC conducted data analysis and wrote the manuscript. SR, BM, PW, and JC provided substantial comments to the writing of the manuscript. All authors read and approved the final manuscript.

Competing interests: None declared.

\section{REFERENCES}

1. McArthur JW, Rasmussen K, Yamey G. How many lives are at stake? Assessing 2030 sustainable development goal trajectories for maternal and child health. BMJ. 2018;360:k373. CrossRef. Medline

2. Doctor HV, Radovich E, Benova L. Time trends in facility-based and private-sector childbirth care: analysis of Demographic and Health Surveys from 25 sub-Saharan African countries from 2000 to 2016. J Glob Health. 2019;9(2):020406. CrossRef. Medline

3. Kruk ME, Gage AD, Joseph NT, Danaei G, García-Saisó S, Salomon JA. Mortality due to low-quality health systems in the universal health coverage era: a systematic analysis of amenable deaths in 137 countries. Lancet. 2018;392(10160):2203-2212. CrossRef. Medline

4. World Health Organization (WHO). Everybody's Business: Strengthening Health Systems to Improve Health Outcomes: WHO's Framework for Action. WHO; 2007. Accessed September 2, 2021. https://apps.who.int/iris/bitstream/handle/10665/43918/ 9789241596077_eng.pdf

5. World Health Organization (WHO), World Bank. Access to Modern Energy Services for Health Facilities in Resource-Constrained Settings. A Review of Status, Significance, Challenges and Measurement. WHO; 2014. Accessed September 2, 2021. https:// apps.who.int/iris/handle/10665/156847

6. Suhlrie L, Bartram J, Burns J, Joca L, Tomaro J, Rehfuess E. The role of energy in health facilities: a conceptual framework and complementary data assessment in Malawi. PLoS One. 2018;13(7):e0200261. CrossRef. Medline

7. Humphreys $G$. Harnessing Africa's untapped solar energy potential for health. Bull World Health Organ. 2014;92(2):82-83. CrossRef. Medline

8. Essendi H, Johnson FA, Madise N, et al. Infrastructural challenges to better health in maternity facilities in rural Kenya: community and healthworker perceptions. Reprod Health. 2015;12(1):103. CrossRef. Medline

9. Munabi-Babigumira S, Glenton C, Willox $M$, Nabudere $H$. Ugandan health workers' and mothers' views and experiences of the quality of maternity care and the use of informal solutions: a qualitative study. PLoS One. 2019;14(3):e021351 1. CrossRef. Medline

10. Cronk R, Bartram J. Environmental conditions in health care facilities in low- and middle-income countries: coverage and inequalities. Int $J$ Hyg Environ Health. 2018;221(3):409-422. CrossRef. Medline

11. Adair-Rohani H, Zukor K, Bonjour S, et al. Limited electricity access in health facilities of sub-Saharan Africa: a systematic review of data on electricity access, sources, and reliability. Glob Health Sci Pract. 2013;1(2):249-261. CrossRef. Medline

12. United Nations Foundation (UN Foundation), Sustainable Energy for All (SEforAll). Lasting Impact: Sustainable Off-Grid Solar Delivery Models to Power Health and Education. UN, SEforAll; 2019. Accessed September 2, 2021. https://www.seforall.org/system/ files/2019-04/Powering-Health_042019.pdf

13. Lee K, Miguel E, Wolfram C. Experimental Evidence on the Demand for and Costs of Rural Electrification. National Bureau of Economic Research; 2016. https://www.nber.org/papers/w22292

14. United States Agency for International Development (USAID), NRECA International Ltd. Guides for Electric Cooperative Development and Rural Electrification. USAID, NRECA International Ltd.; 2016. Accessed September 2, 2021. https://www. nrecainternational.coop/wp-content/uploads/2016/11/ Module6ConsumerWillingnesstoPayandEconomicBenefit AnalysisofRuralElectrificationProject.pdf

15. Leon N, Schneider H, Daviaud E. Applying a framework for assessing the health system challenges to scaling up mHealth in South Africa. BMC Med Inform Decis Mak. 2012;12(1):123. CrossRef. Medline

16. Odendaal WA, Anstey Watkins J, Leon N, et al. Health workers' perceptions and experiences of using mHealth technologies to deliver primary healthcare services: a qualitative evidence synthesis. Cochrane Database Syst Rev. 2020;3(3):CD01 1942. CrossRef. Medline

17. O'Donnell A, Kaner E, Shaw C, Haighton C. Primary care physicians' attitudes to the adoption of electronic medical records: a systematic review and evidence synthesis using the clinical adoption framework. BMC Med Inform Decis Mak. 2018;18(1):101. CrossRef. Medline

18. Kumar P, Paton C, Kirigia D. I've got 99 problems but a phone ain't one: electronic and mobile health in low and middle income countries. Arch Dis Child. 2016;101(10):974-979. CrossRef. Medline

19. Javadi D, Ssempebwa J, Isunju JB, et al. Implementation research on sustainable electrification of rural primary care facilities in Ghana and Uganda. Health Policy Plan. 2020;35(Suppl 2):ii 124-ii 136. CrossRef. Medline

20. Serbanescu F, Goldberg HI, Danel I, et al. Rapid reduction of maternal mortality in Uganda and Zambia through the saving mothers, giving life initiative: results of year 1 evaluation. BMC Pregnancy Childbirth. 2017;17(1):42. CrossRef. Medline

21. Kruk ME, Vail D, Austin-Evelyn K, et al. Evaluation of a maternal health program in Uganda and Zambia finds mixed results on quality of care and satisfaction. Health Aff. 2016;35(3):510-519. CrossRef. Medline

22. Larson E, Mbaruku GM, Cohen J, Kruk ME. Did a quality improvement intervention improve quality of maternal health care? Implementation evaluation from a cluster-randomized controlled study. Int J Qual Health Care. 2020;32(1):54-63. CrossRef. Medline

23. Uganda Bureau of Statistics (UBOS), ICF International. Uganda Demographic and Health Survey 2016. UBOS, ICF International; 2018. Accessed September 2, 2021. https://dhsprogram.com/ pubs/pdf/FR333/FR333.pdf 
24. Uganda Bureau of Statistics (UBOS), ICF International. Uganda Demographic and Health Survey 2011. UBOS, ICF International; 2012. Accessed September 2, 2021. https://dhsprogram.com/ pubs/pdf/FR264/FR264.pdf

25. Rokicki S, Mwesigwa B, Schmucker L, Cohen JL. Shedding light on quality of care: a study protocol for a randomized trial evaluating the impact of the Solar Suitcase in rural health facilities on maternal and newborn care quality in Uganda. BMC Pregnancy Childbirth. 2019;19(1):306. CrossRef. Medline

26. United States Agency for International Development (USAID), Maternal and Child Health Integrated Program (MCHIP). Maternal and newborn quality of care surveys. USAID, Jhpiego; 2013. Accessed September 2, 2021. https://www.mchip.net/qocsurveys/

27. Glasgow RE, Harden SM, Gaglio B, et al. RE-AIM planning and evaluation framework: adapting to new science and practice with a 20-year review. Front Public Health. 2019;7:64. CrossRef. Medline

28. Tripathi V, Stanton C, Strobino D, Bartlett L. Development and validation of an index to measure the quality of facility-based labor and delivery care processes in sub-Saharan Africa. PLoS One. 2015;10 (6):e0129491. CrossRef. Medline

29. MacKinnon JG, Webb MD. The wild bootstrap for few (treated) clusters. Econom J. 2018;21(2):114-135. CrossRef

30. Rokicki S, Cohen J, Fink G, Salomon JA, Landrum MB. Inference with difference-in-differences with a small number of groups. Med Care. 2018;56(1):97-105. CrossRef. Medline

31. Leonard K, Masatu MC. Outpatient process quality evaluation and the Hawthorne Effect. Soc Sci Med. 2006;63(9):2330-2340. CrossRef. Medline

32. World Bank. Service delivery indicators health survey Uganda 2013 - harmonized public use data. World Bank; 2017. Accessed September 3, 2021. https://microdata.worldbank.org/index.php/ catalog/2750/related-materials

33. Uganda Ministry of Health (MOH), Macro International Inc. Uganda Service Provision Assessment Survey 2007. MOH, Macro International Inc.; 2008. Accessed September 3, 2021. hitps://dhsprogram.com/ publications/publication-spal3-spa-final-reports. $f m$

34. World Health Organization (WHO). Medical Devices: Managing the Mismatch. An Outcome of the Priority Medical Devices Project. WHO; 2010. Accessed September 3, 2021. https://apps.who.int/ iris/bistream/handle/10665/44407/9789241564045_eng.pdf

35. Powering health: analyze energy demand and supply. United States Agency for International Development. Updated June 23, 2020. Accessed September 3, 2021. https://www.usaid.gov/energy/ powering-health/analyze-demand-supply

36. Knight HE, Self A, Kennedy SH. Why are women dying when they reach hospital on time? A systematic review of the 'third delay'. PLoS One. 2013;8(5):e63846. CrossRef. Medline
37. Goodman DM, Srofenyoh EK, Olufolabi AJ, Kim SM, Owen MD. The third delay: understanding waiting time for obstetric referrals at a large regional hospital in Ghana. BMC Pregnancy Childbirth. 2017;17(1):216. CrossRef. Medline

38. Kruk ME, Leslie HH, Verguet S, Mbaruku GM, Adanu RMK, Langer A. Quality of basic maternal care functions in health facilities of five African countries: an analysis of national health system surveys. Lancet Glob Health. 2016;4(1 1):e845-e855. CrossRef. Medline

39. Duysburgh $E$, Temmerman $M$, Yé $M$, et al. Quality of antenatal and childbirth care in rural health facilities in Burkina Faso, Ghana and Tanzania: an intervention study. Trop Med Int Health. 2016; 21(1):70-83. CrossRef. Medline

40. Althabe F, Bergel E, Cafferata ML, et al. Strategies for improving the quality of health care in maternal and child health in low-and middle-income countries: an overview of systematic reviews. Paediatr Perinat Epidemiol. 2008;22(Suppl 1):42-60. CrossRef. Medline

41. Kruk ME, Pate M, Mullan Z. Introducing The Lancet Global Health Commission on High-Quality Health Systems in the SDG Era. Lancet Glob Health. 2017;5(5):e480-e481. CrossRef. Medline

42. National Academies of Sciences, Engineering, and Medicine. Crossing the Global Quality Chasm: Improving Health Care Worldwide. The National Academies Press; 2018. Accessed September 3, 2021. http://nationalacademies.org/hmd/Reports/ 2018/crossing-global-quality-chasm-improving-health-careworldwide.aspx

43. Zeng W, Li G, Ahn H, Nguyen HTH, Shepard DS, Nair D. Costeffectiveness of health systems strengthening interventions in improving maternal and child health in low-and middle-income countries: a systematic review. Health Policy Plan. 2018;33(2):283-297. CrossRef. Medline

44. World Health Organization (WHO). World Health Statistics 2016 Monitoring Health for the SDGs Sustainable Development Goals. WHO; 2016. Accessed September 3, 2021. https://apps.who.int/ iris/handle/10665/206498

45. Berwick DM, Kelley E, Kruk ME, Nishtar S, Pate MA. Three global health-care quality reports in 2018. Lancet. 2018;392(10143):194195. CrossRef. Medline

46. Stottlemyer J, Hacker S. Medical Equipment and Clinic Electrification Report. UKAID, CLASP; 2021. Accessed September 3, 2021. https://www.clasp.ngo/research/all/medical-equipment-andclinic-electrification-report/

47. United States Agency for International Development (USAID). Powering Health: Electrification Options for Rural Health Centers. USAID. Accessed September 3, 2021. http://www. poweringhealth. org/Pubs/PNADJ557.pdf

\section{Peer Reviewed}

Received: April 26, 2021; Accepted: August 10, 2021; First published online: December 9, 2021.

Cite this article as: Rokicki S, Mwesigwa B, Waiswa P, Cohen J. Impact of solar light and electricity on the quality and timeliness of maternity care: a stepped-wedge cluster-randomized trial in Uganda. Glob Health Sci Pract. 2021;9(4):777-792. https://doi.org/10.9745/GHSP-D-21-00205

(C) Rokicki et al. This is an open-access article distributed under the terms of the Creative Commons Attribution 4.0 International License (CC BY 4.0), which permits unrestricted use, distribution, and reproduction in any medium, provided the original author and source are properly cited. To view a copy of the license, visit https://creativecommons.org/licenses/by/4.0/. When linking to this article, please use the following permanent link: https:// doi.org/10.9745/GHSP-D-21-00205 